\title{
Comparing the Effect of Insulin Infusion Alone and in Combination of Insulin Infusion with Salbutamol Nebulization in Treatment of Hyperkalemia in Diabetic and Non-Diabetic Patients
}

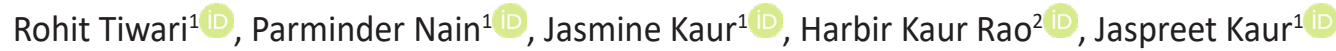 \\ ${ }^{1}$ Maharishi Markandeshwar College of Pharmacy, Department of Pharmacy Practice, Mullana-Ambala (Haryana), India \\ ${ }^{2}$ Maharishi Markandeshwar Institute of Medical Science and Research, Department of Medicine, Mullana-Ambala, India \\ Correspondence Author: Parminder Nain \\ E-mail: parminder.nain26@gmail.com \\ Received: 04.06.2020 Accepted: 06.03.2021
}

\begin{abstract}
Objective: To evaluate the clinical efficacy and comparison of potassium lowering effect of insulin infusion alone and insulin infusion with salbutamol nebulization.

Methods: This interventional study was conducted in a tertiary care hospital, for a period of one year. A total of 190 patients with hyperkalemia were divided into two groups. Group-A (diabetic [D] and non-diabetic [ND] patients) received salbutamol $20 \mathrm{mg}$ three times daily (TDS) (nebulizer $5 \mathrm{mg} / 2.5 \mathrm{~mL}$ ) administered over a period of 15 minutes with 10 units of regular insulin (diluted with $25 \%$ dextrose in non-diabetic only) over 30 minute TDS via infusion. Group-B (diabetic and non-diabetic patients) received 10 units of regular insulin (diluted with $25 \%$ dextrose in non-diabetic patients only) administered over 30 minute TDS via infusion. Potassium and glucose level was measured in patient blood sample after 0, 6, 12 and 24 hrs of treatment.
\end{abstract}

Results: The potassium level was decreased by $30.09 \%$ (D) and 31.98\% (ND) in Group-A, whereas by $31.98 \%$ (D) and 20.49\% (ND) in Group-B, after $24 \mathrm{hrs}$. Whereas blood glucose level in diabetic patients of Group-A and Group-B was found to decrease up to $28.85 \%$ and $40.78 \%$ respectively after 6 hours. Both the treatments were found to be effective without any complication i.e. hypoglycaemia and hypokalaemia. Moreover, renal, liver, cardiac and respiratory function test also did not show significant changes after treatments when recorded bihourly.

Conclusion: From the results, salbutamol nebulizer with insulin is more effective in the treatment of hyperkalemia in diabetic and non-diabetic patients.

Keywords: Hyperkalemia, diabetes, Insulin infusion, Salbutamol nebulizer,

\section{INTRODUCTION}

Hyperkalemia, usually defined as serum potassium concentrations greater than $5.5 \mathrm{mmol} / \mathrm{L}$, is widely recognized as a direct and life-threatening complication. It is encountered more frequently in current medical practices due to the increasing incidence and prevalence of common chronic diseases, such as diabetes and chronic kidney disease, which disturb potassium homeostasis (1). Renal failure is associated with predictable abnormalities in composition of body fluids (2). Hyperkalemia mainly due to failure of renal adaptation to potassium imbalance resulting from a combination of intrinsic and extrinsic factors (3-5). Intrinsic factors includes decreased glomerular filtration rate, decreased distal delivery of sodium, selective reduction in distal tubule secretory function, impaired mineralocorticoid activity, and metabolic disturbances, such as acidosis and hyperglycemia (1). Common extrinsic factors are drugs that impair physiologic responses to hyperkalemia (e.g., various inhibitors of the renin-angiotensin-aldosterone system
(RAAS), and potassium intake (e.g., a diet rich in potassium, or potassium supplements) (6). The frequency of chronic hyperkalemia is increased in current medical practice because RAAS inhibitors have undisputed beneficial effects in patient groups that are most susceptible to the development of hyperkalemia; for example, patients with chronic kidney disease (CKD), diabetes mellitus, or congestive heart failure (7). Intracellular shift of potassium is major defense against acute rise in serum potassium levels in patients with renal failure (8-9). Insulin via infusion and epinephrine are two major physiologic factors which promote this extrarenal potassium disposal (6). Renal potassium excretion is an effective but time consuming treatment for potassium homeostasis. During this long period of time, additional renal mechanism which are in action within minutes useful to lower acute potassium load (8).

In the management of hyperkalemia, combination therapy with an angiotensin-converting enzyme (ACE) inhibitor and 
an angiotensin receptor blocker (ARB) should not be used in diabetic and non-diabetic patients with CKD and hypertension because more adverse events like severe hyperkalemia, kidney dysfunction, and hypotension can occur without any increase in benefits (10-12). Aggravating kidney function and hyperkalemia can arise in some CKD patients after starting Renin-Angiotensin-Aldosterone System (RAAS) inhibitor (ACE-I or ARB), it can lower glomerular filtration rate and can slower potassium secretion. Therefore, it is useful to monitor serum potassium and roughly glomerular filtration rate within several weeks of starting or accelerating a RAAS (13). Terminating these drugs is helpful in controlling or treating hyperkalemia, but it can enhance the risk for kidney disease advancement and cardiovascular events.

The spectrum of hyperkalemia ranges from single episodes, sustained, recurrent or severe cases of hyperkalemia that require dialysis; but consistently mild, moderate, or severe hyperkalemia are not defined. Moreover, the cardio toxic effects of a particular potassium concentration depend on the baseline value, the rate of increase in potassium concentration, as well as the acid-base status, and serum calcium concentration (14). Mild to moderate hyperkalemia is commonly asymptomatic. Patients with moderate to severe hyperkalemia may complain of nausea, palpitations, muscle weakness, or paresthesia. Therefore, moderate and especially severe hyperkalemia can lead to cardiac arrhythmias and conduction abnormalities that may be dangerous. Rapid decline in serum potassium is generated by administration of insulin via infusion and salbutamol (nebulization) but electrocardiographic (ECG) changes is a medical emergency (15). Intravenous calcium gluconate should be given in patients with characteristic ECG changes because of hyperkalemia. Lower the potassium by giving intravenous insulin with glucose or a beta ${ }_{2}$ agonist by nebulizer, or both. Total body potassium should usually be lowered with sodium polystyrene sulfonate. (16-18). The aim of our study was to evaluate the clinical efficacy and comparison of potassium lowering effects of insulin infusion alone and insulin infusion with salbutamol nebulization in diabetic and non-diabetic patients.

\section{METHODS}

\subsection{Study Design}

A prospective observational study was conducted in tertiary care hospital for a period from July 2018 to June 2019. Total patient included in this current study from Medical Intensive Care Unit (MICU) and their medical case files were used to note the relevant clinical information in specific case record form (CRF). A total of 190 patients were enrolled after analysis of their present illness and on the bases of inclusion/ exclusion criteria. Patients having serum potassium level more than $6 \mathrm{mmol} / \mathrm{L}$ were included in the study. The patients having an Ischemic heart disease and already receiving one or more of the following drugs i.e. Beta blocker, digoxin, beta agonist and diuretic therapy were excluded from study. These patients were randomly divided into two groups (Group-A \& Group-B) and each group having ninety five (95) patients. These two groups were further categorized into diabetic (D) and non-diabetic (ND). Group A received salbutamol $20 \mathrm{mg}$ TDS (nebulizer $5 \mathrm{mg} / 2.5 \mathrm{~mL}$ ) administered over a period of 15 minutes with 10 units of regular insulin (Insulin diluted with $25 \%$ dextrose only in non-diabetic patients) administered over 30 minute TDS via infusion. Group B received 10 units of regular insulin (Insulin diluted with 25\% dextrose only in non-diabetic patients) administered over 30 minute TDS via infusion only. Blood samples were taken immediately after starting the treatment i.e. $0 \mathrm{~min}$ (at the time of treatment means 30 min after meal), 6, 12 and 24 hrs after treatment. Potassium and glucose levels were measured in these samples. Blood pressure, pulse, temperature, respiratory rate were monitored during the study period. Electrocardiography (ECG) was recorded for each patient at specified interval. During the study period patients were given treatment according the protocol and patients were not received any other medication that effecting serum potassium levels like furosemide, bicarbonate, beta blockers. Any unwanted effects observed or complained by the patient were recorded. The study protocol was approved by Institutional Ethic Committee (MMIEC/2019/1314). All patients provided the written informed consent to participate after a full explanation of the study. The current study was conducted in accordance with the code of Good Clinical Practice (GCP). Results are expressed as Mean \pm standard deviation (SD). The level of significance established at a $P$ value of less than 0.05 .

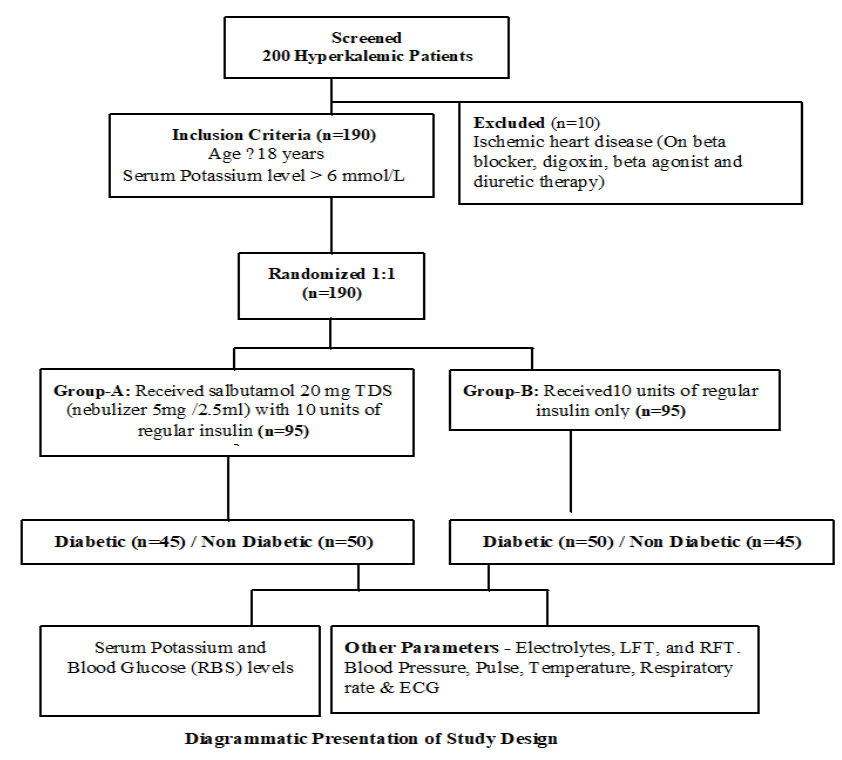

Figure 1. Study Design

\section{RESULTS}

In this study, total number of patient encountered were one hundred ninety $(n=190)$. Out of them 95 patient were received insulin via infusion with salbutamol (nebulization) (Group-A) and other ninety five $(n=95)$ were received 
insulin via infusion alone (Group-B) (Fig 1). On the basis of demographic details, most of patients in both the Group-A and Group-B were in range of 51-65 year of age (Table-1). Majority of patients were male 62 (95) i.e. $65 \%$ in both the groups while female patients were lesser only 33(95) i.e. $35 \%$ in both the groups respectively. The percentage of diabetic and non-diabetic patients in Group-A were $47 \%$ and $53 \%$ and in group $B$ were $53 \%$ and $47 \%$ respectively.

Table 1. Distribution of patients on the basis of age

\begin{tabular}{|lcccc|} 
Group & $\begin{array}{c}\text { Group-A: Insulin via infusion } \\
\text { with Salbutamol (nebulization) } \\
(\mathbf{n}=95)\end{array}$ & $\begin{array}{c}\text { Group-B: Insulin via } \\
\text { infusion }(\mathbf{n}=95)\end{array}$ \\
\hline Age & No. of Patient & Percentage & $\begin{array}{c}\text { No. of } \\
\text { Patient }\end{array}$ & Percentage \\
\hline $35-50$ & 39 & $41 \%$ & 34 & $36 \%$ \\
\hline $51-65$ & 44 & $46 \%$ & 45 & $47 \%$ \\
\hline $66-80$ & 12 & $13 \%$ & 16 & $17 \%$ \\
\hline
\end{tabular}

(Results showed in percentage)

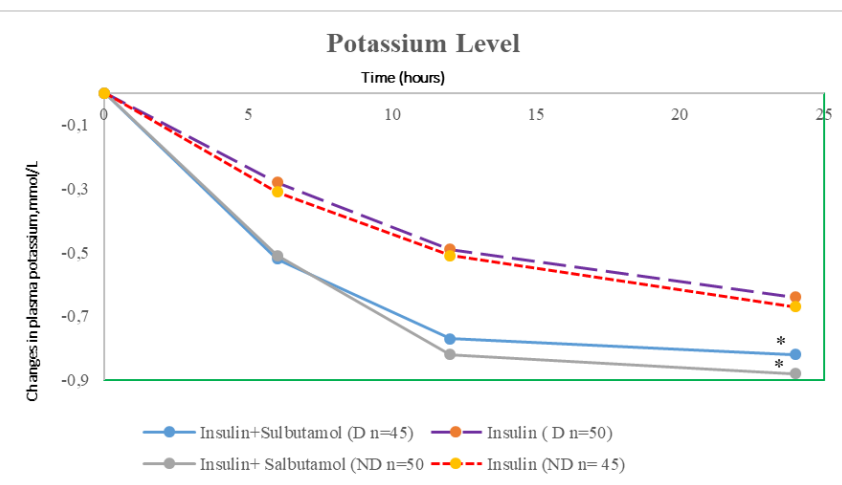

Figure 2. Comparison of Potassium level between group A (Insulin via infusion with Salbutamol nebulization) and group $B$ (Insulin via infusion) after 6, 12, 24 hours of interval in diabetic (D) and Non Diabetic (ND) patients. ${ }^{*} p<0.05$ other treatment regimens group.

Table 2. Comparison between group $A$ and group $B$ on potassium level after 6, 12, 24 hours of interval in diabetic and non-diabetics patients

\begin{tabular}{|lcccc|}
\hline $\begin{array}{l}\text { Laboratory } \\
\text { parameter }\end{array}$ & $\begin{array}{c}\text { Group-A : Insulin (infusion) } \\
\text { with } \\
\text { Salbutamol (nebulization) } \\
\text { (D n=45) }\end{array}$ & $\begin{array}{c}\text { (ND n=50) } \\
\text { Group-B: Insulin } \\
\text { (infusion) alone } \\
\text { (D n=50) (ND n=45) }\end{array}$ \\
\hline $\begin{array}{l}\text { Potassium } \\
\text { (Initial) }\end{array}$ & $7.01 \pm 0.61$ & $6.91 \pm 0.45$ & $6.88 \pm 0.54$ & $6.76 \pm 0.72$ \\
$\begin{array}{l}\text { Potassium } \\
\text { (after 6 hours) }\end{array}$ & $6.49 \pm 0.76$ & $6.40 \pm 0.66$ & $6.60 \pm 0.73$ & $6.45 \pm 0.56$ \\
$\begin{array}{l}\text { Potassium } \\
\text { (after 12 hours) }\end{array}$ & $5.72 \pm 0.50$ & $5.58 \pm 0.48$ & $6.11 \pm 0.69$ & $5.94 \pm 0.65$ \\
$\begin{array}{l}\text { Potassium } \\
\text { (after 24 hours) }\end{array}$ & $4.90 \pm 0.54^{*}$ & $4.70 \pm 0.51 *$ & $5.47 \pm 0.62$ & $5.27 \pm 0.59$ \\
$\begin{array}{l}\% \text { Decreased } \\
\text { (After 24 hours) }\end{array}$ & $30.09 \%$ & $31.98 \%$ & $20.49 \%$ & $22.04 \%$ \\
\hline
\end{tabular}

${ }^{*} p<0.05$ consider as significant when compare with initial level of Potassium in serum.

Values are in mean \pm standard deviation (Units $-\mathrm{mmol} / \mathrm{L}$ )
The plasma potassium concentration at baseline (initial) was approximately similar in all the patients of both the groups (Fig 2). The results clearly showed that the serum potassium levels was started to fall in both the group after initiation of therapy. Serum potassium level in diabetic patients $(7.01 \pm 0.61 \mathrm{mmol} / \mathrm{L}$ to $4.90 \pm 0.64 \mathrm{mmol} / \mathrm{L})(30.09 \%)$ and nondiabetic patients $(6.91 \pm 0.45$ to $4.70 \pm 0.51 \mathrm{mmol} / \mathrm{L})$ (31.98 $\%)$ of Group-A was significantly $(p<0.05)$ decreased after 24 hours of treatment (Table-2). But the level of serum potassium in diabetic patients $(6.88 \pm 0.54 \mathrm{mmol} / \mathrm{L}$ to $5.47 \pm 0.62 \mathrm{mmol} / \mathrm{L})$ $(20.49 \%)$ and non-diabetic patients $(6.76 \pm 0.72 \mathrm{mmol} / \mathrm{L}$ to $5.27 \pm 0.59 \mathrm{mmol} / \mathrm{L})(22.04 \%)$ of Group-B was not significantly decreased after 24 hours of treatment.

The mean \pm SD blood glucose level in diabetic and non-diabetic patients after $6 \mathrm{hrs}$ of treatment in Group-A were $151 \pm 13 \mathrm{mg} / \mathrm{dL}$ and $104 \pm 6 \mathrm{mg} / \mathrm{dL}$, respectively. Moreover, in Group-B the mean \pm SD blood glucose level in diabetic and non-diabetic patients after $6 \mathrm{~h}$ were $180 \pm 21 \mathrm{mg} / \mathrm{dL}$ and $101 \pm 10 \mathrm{mg} / \mathrm{dL}$, respectively (Table 3). In both the groups, the blood glucose level in nondiabetic patients was controlled (not significant change) with dextrose infusion but in diabetic patients the level of blood glucose was significantly decreased i.e. $40.78 \%$ (Group-A) and $28.85 \%$ (Group-B) respectively, $6 \mathrm{hrs}$ after the treatment.

Table 3. Comparison between group $A$ and group $B$ on blood glucose

\begin{tabular}{|llllll|}
\hline $\begin{array}{l}\text { Laboratory } \\
\text { parameter }\end{array}$ & Time & $\begin{array}{l}\text { Group-A: } \\
\text { via infusion } \begin{array}{r}\text { Insulin Group-B: Insulin via } \\
\text { with infusion }\end{array}\end{array}$ \\
\hline & $0 \mathrm{~min}$ & $\mathrm{D}(\mathrm{n}-45)$ & $\mathrm{ND}(\mathrm{n}=50)$ & $\mathrm{D}(\mathrm{n}=50)$ & $\mathrm{ND}(\mathrm{n}=45)$ \\
& $0 \mathrm{~min} \pm 32$ & $103 \pm 11$ & $253 \pm 37$ & $109 \pm 12$ \\
Blood glucose & $1 \mathrm{hr}$ & $200 \pm 16$ & $112 \pm 9$ & $209 \pm 27$ & $107 \pm 11$ \\
concentration & $3 \mathrm{hr}$ & $175 \pm 11$ & $110 \pm 10$ & $189 \pm 19$ & $101 \pm 8$ \\
(mg/dL) & $6 \mathrm{hr}$ & $151 \pm 13^{*}$ & $104 \pm 6$ & $180 \pm 21 *$ & $101 \pm 10$ \\
& $\%$ & 40.78 & 5.4 & 28.85 & 7.3 \\
\hline
\end{tabular}

$D=$ Diabetic; $N D=$ Non Diabetic, ${ }^{*} p<0.05 ;$ Values are in mean \pm standard deviation

$0 \mathrm{~min}$ (initial reading or at the time of Treatment) means 30 min after meal. The results clearly indicates that, there is no significant difference and changes in the level of Liver Function Test (LFT i.e. SGOT, SGPT, alkaline phosphatase) (Fig 3), Renal Function Test (RFT i.e. urea, creatinine, uric acid) (Fig 4), and the level of electrolytes (i.e. sodium \& chloride) (Fig 5 ) in group $A$ and group $B$ respectively after and before the treatment (Table-4).

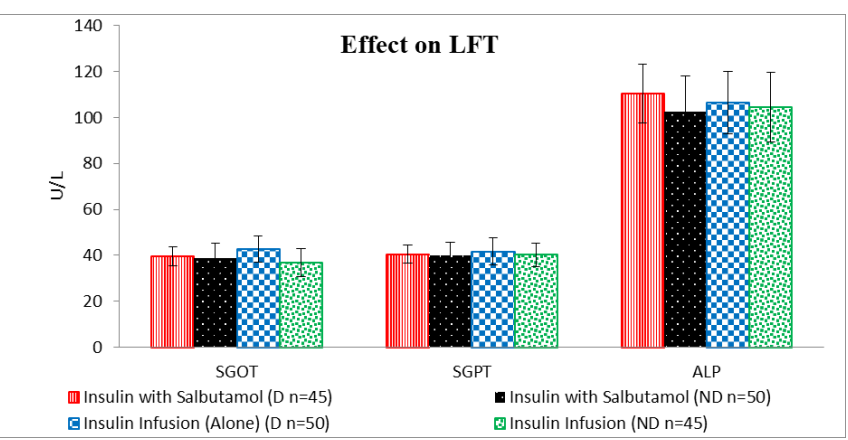

Figure 3. Comparison of LFT parameter (SGOT, SGPT, ALP) between group A (Insulin via infusion with Salbutamol nebulization) and group B (Insulin via infusion) in diabetic and Non Diabetic Patients. 


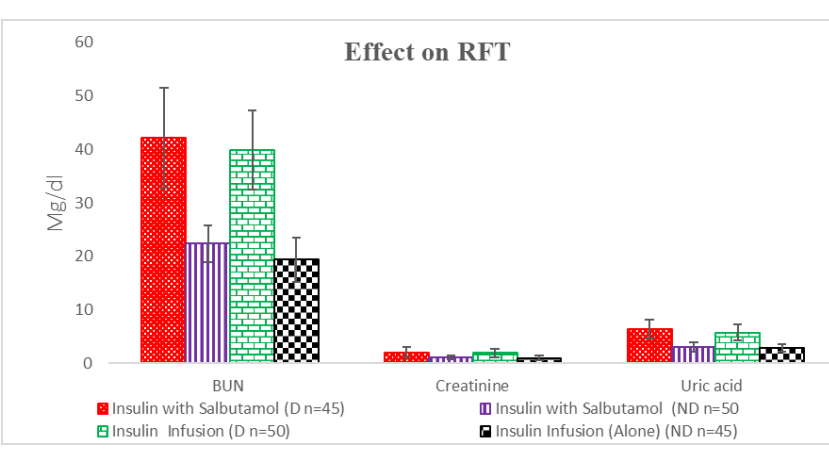

Figure 4. Comparison of RFT parameters (urea, creatinine, uric acid) between group A (Insulin via infusion with Salbutamol nebulization) and group $B$ (Insulin via infusion) in diabetic and non-diabetic patients

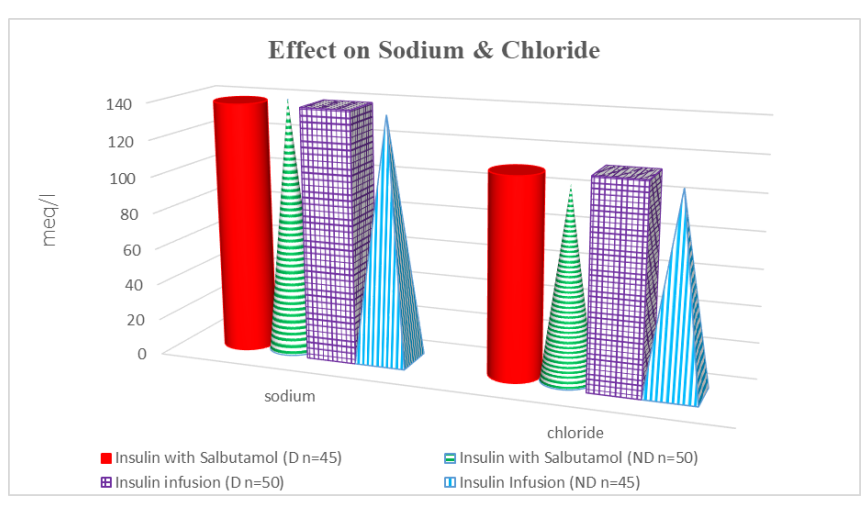

Figure 5. Comparison of electrolytes (sodium, \& chloride) between group A (Insulin via infusion with Salbutamol nebulization) and group B (Insulin via infusion alone) in diabetic and non-diabetic patient

Table 4. Comparison of various biochemical parameters between group $A$ and group $B$

\begin{tabular}{|c|c|c|c|c|c|}
\hline \multirow[t]{2}{*}{ System } & \multirow[t]{2}{*}{ Parameters } & \multicolumn{2}{|c|}{ Group-A } & \multicolumn{2}{|c|}{ Group-B } \\
\hline & & Before Treatment & $\begin{array}{l}\text { After } 24 \text { hrs of } \\
\text { Treatment }\end{array}$ & $\begin{array}{l}\text { Before } \\
\text { Treatment }\end{array}$ & $\begin{array}{l}\text { After } 24 \mathrm{hrs} \text { of } \\
\text { Treatment }\end{array}$ \\
\hline \multirow{4}{*}{ Blood Pressure } & Systolic (mmHg) & $132.21 \pm 11.25$ & $127.42 \pm 13.86$ & $129.32 \pm 8.9$ & $122.11 \pm 7.6$ \\
\hline & Diastolic (mmHg) & $83.03 \pm 9.12$ & $76.94 \pm 10.16$ & $80.37 \pm 5.8$ & $79.51 \pm 7.7$ \\
\hline & Heart Rate (Beats / Minute) & & & & \\
\hline & & $85.11 \pm 6.65$ & $81.88 \pm 8.44$ & $80.15 \pm 7.27$ & $78.08 \pm 5.80$ \\
\hline \multirow{2}{*}{$\begin{array}{l}\text { Respiratory } \\
\text { System }\end{array}$} & $\begin{array}{l}\text { Respiratory Rate (Breaths / } \\
\text { minute) }\end{array}$ & $21.09 \pm 1.97$ & $20.22 \pm 2.24$ & $20.35 \pm 1.09$ & $20.08 \pm 1.77$ \\
\hline & $\begin{array}{l}\text { Arterial Oxygen Saturation } \\
\text { (\%) }\end{array}$ & $94.31 \pm 6.80$ & $95.12 \pm 4.65$ & $93.48 \pm 4.72$ & $94.36 \pm 4.19$ \\
\hline \multirow{3}{*}{ Haemogram Test } & $\mathrm{HB}(\mathrm{g} / \mathrm{dL})$ & $11.98 \pm 1.98$ & $12.04 \pm 1.66$ & $10.62 \pm 1.19$ & $10.96 \pm 2.20$ \\
\hline & TLC (10 $/$ /iter) & $11.35 \pm 1.79$ & $11.99 \pm 1.16$ & $7 \pm 0.97$ & $7 \pm 1.09$ \\
\hline & Platelet $\left(10^{9} /\right.$ liter $)$ & $2.81 \pm 0.21$ & $2.89 \pm 0.43$ & $3.42 \pm 0.54$ & $3.45 \pm 0.90$ \\
\hline \multirow{7}{*}{ Liver Panel Tests } & Total Bilirubin (mg/dL) & $0.96 \pm 0.15$ & $0.90 \pm 0.26$ & $0.95 \pm 0.20$ & $0.89 \pm 0.35$ \\
\hline & Direct Bilirubin (mg/dL) & $0.33 \pm 0.04$ & $0.31 \pm 0.19$ & $0.34 \pm 0.09$ & $0.33 \pm 0.11$ \\
\hline & Total Protein (g/dl) & $6.81 \pm 0.90$ & $7.02 \pm 0.94$ & $6.51 \pm 1.44$ & $6.79 \pm 1.12$ \\
\hline & Serum Albumin (gm/dl) & $3.41 \pm 0.55$ & $3.56 \pm 0.70$ & $3.39 \pm 0.62$ & $3.44 \pm 0.75$ \\
\hline & SGOT (U/L) & $39.65 \pm 4.2$ & $40.05 \pm 3.9$ & $38.95 \pm 8.48$ & $38.40 \pm 6.71$ \\
\hline & SGPT (U/L) & $40.07 \pm 4.11$ & $40.59 \pm 3.92$ & $39.90 \pm 8.66$ & $38.83 \pm 5.87$ \\
\hline & ALP (IU/L) & $105.48 \pm 17.7$ & $102.35 \pm 10.1$ & $103.6 \pm 19.62$ & $102.6 \pm 13.31$ \\
\hline \multirow{3}{*}{$\begin{array}{l}\text { Renal Function } \\
\text { Test }\end{array}$} & Blood Urea Nitrogen $(\mathrm{mg} / \mathrm{dL})$ & $22.25 \pm 3.71$ & $21.98 \pm 3.24$ & $27.51 \pm 5.5$ & $26.23 \pm 6.1$ \\
\hline & Serum Creatinine (mg/dL) & $3.96 \pm 0.33$ & $3.04 \pm 0.29$ & $3.62 \pm 0.39$ & $3.23 \pm 0.52$ \\
\hline & Serum Uric acid (mg/dL) & $7.01 \pm 0.69$ & $6.94 \pm 0.90$ & $6.7 \pm 0.50$ & $6.6 \pm 0.54$ \\
\hline \multirow[b]{2}{*}{ Electrolytes } & Sodium (mEq/L) & $140.28 \pm 10.87$ & $135.28 \pm 12.30$ & $139.62 \pm 6.28$ & $138.62 \pm 7.39$ \\
\hline & Chloride (mEq/L) & $100.94 \pm 6.05$ & $101.36 \pm 7.033$ & $101.74 \pm 6.10$ & $103.09 \pm 5.35$ \\
\hline
\end{tabular}

${ }^{*} p<0.05$ consider as significant when compare with initial level. Values are in mean \pm standard deviation 
No significant change was noted in heart rate, blood pressure, temperature, respiratory rate and electrocardiogram. All the treatment modalities were well tolerated. No side effect in any patient was noted.

\section{DISCUSSION}

Regulation of potassium in the nephron depends on passive and active mechanisms. Potassium is filtered in the glomerulus and approximately $60-75 \%$ of the filtered potassium is reabsorbed in the proximal tubule (PT) by diffusion. Approximately $15-20 \%$ of the filtered potassium is reabsorbed in the thick ascending limb of the Loop of Henle by several co-transporters and ion channels. Excretion mainly occurs in the cortical collecting duct (19). Hyperkalemia may result by an increase in total body potassium secondary to imbalance of intake vs. excretion or from maldistribution between intra and extracellular space. Acid-base balance can affect the balance between cellular and extracellular potassium concentration. Acidosis increases the plasma $\mathrm{K}^{+}$ concentration by inducing a net shift of $\mathrm{K}^{+}$from the cellular to the extracellular compartment in exchange with $\mathrm{H}^{+}$, also leading to a reduced tubular secretion of potassium (20). Low level of insulin in diabetes mellitus results to accumulation of potassium in the extracellular space. Insulin shifts potassium into cells by stimulating the activity of $\mathrm{Na}^{+}-\mathrm{H}^{+}$antiporter on cell membrane, promoting the entry of sodium into cells, which leads to activation of the $\mathrm{Na}^{+}-\mathrm{K}^{+}$ATPase and inhibition of potassium efflux (21).

In clinical Practice management of hyperkalemia provide only transitory improvement by shifting $\mathrm{K}^{+}$into intracellular space without actually eliminating potassium. Insulin infusion/dextrose administration is important in preventing a large change in extracellular fluid (ECF) $\mathrm{K}^{+}$ concentration as it increases potassium uptake into liver and muscle cells by stimulating $\mathrm{Na}^{+} / \mathrm{K}^{+}$ATPase. Moreover, beta-adrenergic agonists (salbutamol) bind to beta-2 receptors on muscle cells, stimulate $\mathrm{Na}^{+} / \mathrm{K}^{+}$ATPase and increase $\mathrm{K}^{+}$shift into cells (22). Salbutamol can be applied via nebulizer or given intravenously. It was reported that, salbutamol via nebulizer has a profound effect in lowering the serum potassium level in dose dependent manner but several limitations associated such as tremor, hypokalemia, hyperglycemic ketoacidosis and tachycardia (23-24). Therefore, we were investigating and comparing the effect of these modalities with mentioned possibility in diabetic and non-diabetic patients.

According to the results of this studies, the mean potassium level in group A (both diabetic and non-diabetic patients) was significantly reduced within twenty four hours of treatment administration. This finding is consistent with results of a multi-systemic review study in which it was reported that the significant decrease level of potassium occur after 60 min of treatment (3). Decrease in mean potassium levels was (D-30.09\%) and (ND-31.98 \%) in Group-A (treated by insulin infusion with salbutamol nebulization) than Group-B (insulin infusion alone) probably due to the stimulation of beta - adrenergic receptors in pancreas resulting in insulin release which causes an additive effect. Our study showed that there was slightly increase in blood glucose level after one hour of nebulized salbutamol only in non-diabetic patients, this finding is similar to results of previous study (25). Moreover, in the current study, electrolytes, LFT, RFT was not significantly changed in both treated groups. Appropriate care and close monitoring should be considered during treatment of non-diabetic patients by insulin infusion with nebulized salbutamol.

\section{CONCLUSION}

In treatment of hyperkalemia, the combination of medications with different therapeutic approaches is usually effective. Our study confirms that, insulin infusion (intravenous) and beta-adrenergic agonist's nebulization have the quickest onset and appear to be effective and safe when administered together, than intravenous insulin infusion alone in diabetic and non-diabetic patients. Ideally combination should be preferred under control conditions for treating hyperkalemia without hypokalemia and hyperglycemic ketoacidosis.

Acknowledgments: We are thankful to M.M. Super-Speciality Hospital.

\section{REFERENCES}

[1] Fried L, Kovesdy CP, Palmer BF. New options for the management of chronic hyperkalemia. Kidney International (Suppl) 2017; 7: 164-70.

[2] Spital A, Freedman Z. Severe hypercalcemia in a woman with renal failure. American Journal of kidney Diseases 1995; 26 : 674-7.

[3] Mushtaq MA, Masood M. Treatment of hyperkalemia with salbutamol and insulin. Pakistan Journal of Medical Sciences 2006; 22: 176 .

[4] Allon M. Treatment and prevention of hyperkalemia in endstage renal disease. Kidney International 1993; 43:1197-209.

[5] Kovesdy CP. Management of hyperkalemia in chronic kidney disease. Nature Reviews Nephrology 2014; 10: 653.

[6] Palmer BF. Managing hyperkalemia caused by inhibitors of the renin-angiotensin-aldosterone system. New England Journal of Medicine 2004; 351: 585-92.

[7] Palmer BF. Hyperkalemia in pre-dialysis patients. Clinical Journal of the American Society of Nephrology 2012; 7: 12012.

[8] Palmer BF, Clegg DJ. Achieving the benefits of a highpotassium, paleolithic diet, without the toxicity. Mayo Clinic Proceedings 2016; 91: 496-508.

[9] Maxwell and Kleeman. Clinical Disorders of Fluid and Electrolyte Metabolism, Fifth Edition. 1994. Robert G. Narins (Editor), Publish by McGraw-Hill, New York.

[10] Mann JF, Anderson C, Gao P, Gerstein HC, Boehm M, Rydén $L$, Sleight P, Teo KK, Yusuf S; ONTARGET investigators. Dual inhibition of the renin-angiotensin system in high-risk diabetes and risk for stroke and other outcomes: results of the ONTARGET trial. Journal of Hypertension 2013; 31: 414-421. 
[11] Fried LF, Duckworth W, Zhang JH, O'Connor T, Brophy M, Emanuele N, Huang GD, McCullough PA, Palevsky PM, Seliger $S$, Warren SR, Peduzzi P; VA NEPHRON-D Investigators. Design of combination angiotensin receptor blocker and angiotensinconverting enzyme inhibitor for treatment of diabetic nephropathy. Clinical Journal of the American Society of Nephrology 2009; 4: 361-8.

[12] Parving HH, Brenner BM, McMurray JJ, de Zeeuw D, Haffner SM, Solomon SD, Chaturvedi N, Persson F, Desai AS, Nicolaides M, Richard A, Xiang Z, Brunel P, Pfeffer MA; ALTITUDE Investigators. Cardiorenal end points in a trial of aliskiren for type 2 diabetes. New England Journal of Medicine 2012; 367: 2204-13.

[13] Vassalotti JA, Centor R, Turner BJ, Greer RC, Choi M, Sequist TD; National Kidney Foundation Kidney Disease Outcomes Quality Initiative. Practical approach to detection and management of chronic kidney disease for the primary care clinician. Am J Med 2016; 129: 153-62.

[14] Epstein M. Hyperkalemia as a constraint to therapy with combination Renin-Angiotensin System blockade: The elephant in the room. The Journal of Clinical Hypertension 2009; 11: 55-60.

[15] Liou HH, Chiang SS, Wu SC, Huang TP, Campese VM, Smogorzewski M, Yang WC. Hypokalemic effects of intravenous infusion or nebulization of salbutamol in patients with chronic renal failure: comparative study. American Journal of kidney Diseases 1994; 23: 266-271.

[16] Mehta RL. Therapeutic alternatives to renal replacement for critically ill patients in acute renal failure. Seminars in Nephrology 1994; 14: 64-82
[17] Rahman SN, Kim GE, Mathew AS, Goldberg CA, Allgren R, Schrier RW, Conger JD. Effects of atrial natriuretic peptide in clinical acute renal failure. Kidney Int 1994; 45: 1731-1738.

[18] Allon M, Shanklin N. Effect of albuterol treatment on subsequent dialytic s potassium removal. American Journal of kidney Diseases 1995; 26: 607-13.

[19] Mount DB. Thick ascending limb of the loop of Henle. Clinical Journal of the American Society of Nephrology 2014; 9: 19741986.

[20] Aronson PS, Giebisch G. Effects of pH on potassium: new explanations for old observations. Journal of the American Society of Nephrology 2011; 22: 1981-1989.

[21] Li T, Vijayan A. Insulin for the treatment of hyperkalemia: a double-edged sword? Clinical Kidney Journal 2014; 7: 239241.

[22] Al-Azzawi OFN, Obaidy MWA, Shihab DM, The effect of nebulized salbutamol on serum potassium and blood sugar level of asthmatic patients. Global Journal of Health Science 2018; 10 (9); 25-32.

[23] Johns R, Roberts CM. Nebulisers: their effectiveness, indications and limitations. The Journal of Prescribing and Medicines Management 2007; 18: 16-28.

[24] Pandya D, Puttanna A, Balagopal V. Systemic Effects of Inhaled Corticosteroids: An Overview. The Open Respiratory Medicine Journal 2014; 8: 59.

[25] Sears MR, Lötvall J. Past, present and future- $\beta 2$-adrenoceptor agonists in asthma management. Respiratory Medicine 2005; 99: 152-70.

How to cite this article: Tiwari R, Nain P, Kaur J, Rao HK, Kaur J. Comparing the Effect of Insulin Infusion Alone and in Combination of Insulin Infusion with Salbutamol Nebulization in Treatment of Hyperkalemia in Diabetic and Non-Diabetic Patients. Clin Exp Health Sci 2021; 11: 412-417. DOI: 10.33808/clinexphealthsci.747900 